\title{
The Prevalence of distorted terminal portion of QRS complex in patients of CKD with STEMI and its effect on their Outcome
}

\author{
KHANDAKER AISHA SIDDIKA ${ }^{1}$, MD. ABU SIDDIQUE ${ }^{1}$, SHAMIM AHASAN ${ }^{1}$, ARIF HOSSAIN ${ }^{1}$, \\ ARIF MOHAMMAD SOHAN ${ }^{1}$, MD. FAKHRUL ISLAM KHALED ${ }^{1}$, TANJIMA PARVIN ${ }^{1}$, DIPAL K. ADHIKARY ${ }^{1}$, \\ SOHEL MAHMUD ${ }^{1}$, DMMF OSMANY ${ }^{1}$, NASIMUL BARI ${ }^{2}$, SM MUSTAFA ZAMAN $^{2}$, HARISUL HOQUE $^{1}$ \\ ${ }^{1}$ Department of Cardiology, Bangabandhu Sheikh Mujib Medical University, Dhaka, ${ }^{2}$ Kustia Sadar Hospital, Kustia
}

Address of Correspondence: Dr. Khandaker Aisha Siddika, Department of Cardiology, Bangabandhu Sheikh Mujib Medical University, Shahbag, Dhaka, e-mail: dr.aishajahangir.bsmmu@gmail.com

\begin{abstract}
:
Background: Distorted terminal portion of QRS complex on initial electrocardiogram (ECG) in patients with ST segment elevation myocardial infarction ( STEMI) is a strong predictor of adverse outcome. Objectives: Our purpose of this study was to assess the relationship of distortion of QRS on initial ECG in STEMI with chronic kidney diseases (CKD). Methods: We evaluated 60 patients of STEMI admitted within 12 hours and receiving thrombolytic therapy. Patients having serum creatinine $<1.5 \mathrm{mg} / \mathrm{dl}$ were group-I and $\geq 1.5 \mathrm{mg} / \mathrm{dl}$ were group-II. We defined two ECG groups according to absence of distortion of terminal QRS and presence of distorted terminal QRS in two or more adjacent leads. Distorted QRS group further divided into pattern-A$J$ point originating at $\geq 50 \%$ of height of $R$ wave in leads with $q R$ configuration and pattern $B-S$ wave is absent in leads with RS configuration. Additionally study population was divided into two groups on the basis of serum creatinine level. Results: CKD patients had more QRS distortion $(43.2 \%$ vs $68.8 \%, p=0.008)$ and worse inhospital outcome. Out of 60 patients $7(11.6 \%)$ death, 16(26.7\%) heart failure and 37(61.7\%) uneventful recovery. Hospital mortality and heart failure were significantly higher in STEMI with CKD group (4.5\% vs $31 \%, p=0.004 ; 16 \%$ vs $56 \%, p=0.001$; respectively), uneventful recovery was significantly higher in STEMI without CKD group $(12.5 \%$ vs $80 \%, p=<0.001)$. In multiple logistic regression analysis, $C K D$ ( serum creatinine $\geq 1.5)$ and Killip class $\geq I I$ were independent predictors of $Q R S$ distortion $(O R=5.702, p=0.014 ; O R=$ 3.578,p=0.036; respectively). Conclusion: Among the CKD patients with STEMI the distorted terminal portion of QRS complex on initial ECG is more frequent and significantly related to adverse prognosis. Careful analysis of ECG which is simple, chief, universally available, bed side investigation may offer important information regarding prompt risk stratification and management in patients of CKD with STEMI.
\end{abstract}

Key words: STEMI, CKD, Distorted QRS.

Introduction:

Chronic Kidney diseases and acute coronary syndrome (ACS) are wide spread diseases and they affect many individuals worldwide. Number one cause of death in patients with CKD is coronary artery diseases ${ }^{---1}$. Patients with STEMI and renal dysfunction had a six fold higher one eighty days mortality than the patients with normal renal function $\quad(16.2 \%$ vs $2.5 \%, \mathrm{p}<0.001)$ in GUSTO $\mathrm{IIb}^{2}$. CKD is defined as kidney damage e” 3 months with or without decrease $\mathrm{GFR}^{2}$. Presentation of patients with CKD and STEMI at admission is atypical specially patients on dialysis than nondialysis ${ }^{2}$. Regarding management of these patients, fibrinolysis or primary PCI did not improve inhospital mortality ${ }^{1}$. So there is great importance of primary prevention and risk factor modification to prevent the progression of CKD and cardiovascular diseases. On the other hand, the distortion of the terminal portion of QRS complex on initial electrocardiogram (ECG) in patients with
STEMI has been found to be predictive of adverse outcome $^{3,4}$. The purpose of this study was to analyze the prevalence of this ECG pattern in patients with CKD with STEMI and its influence on their prognosis.

Methods:

Patients: This observational prospective study was conducted in BSMMU during the period of July 2014 to June 2015. We studied 60 patients of STEMI admitted within 12 hours of onset of chest pain which lasted for at least 30 minutes and receiving thrombolytic therapy. STEMI was diagnosed when ECG showing ST elevation of $1 \mathrm{~mm}$ or more in two or more consecutive leads often with reciprocal ST depression in the contralateral leads, except in leads V2-V3 where $\geq 2 \mathrm{~mm}$ of ST elevation in men with age $\geq 40$ years, $\geq 2.5 \mathrm{~mm}$ men with age $<40$ years and $\geq$ $1.5 \mathrm{~mm}$ in women were required for accurate diagnosis ${ }^{5}$ with positive T waves in leads with ST segment elevation 
with increase in cardiac enzymes. Patients with admitted after 12 hours of STEMI and who had absolute contraindication of Streptokinase, left bundle branch block (LBBB), ventricular arrhythmias (Ventricular tachycardia, Ventricular fibrillation) at admission, ventricular pacing or negative $\mathrm{T}$ waves in leads demonstrating ST segment elevation, acute renal failure were excluded. Clinical assessment was done and various risk factors were noted. Standard medication were received as per the direction of the treating physician. Serum creatinine was done in each patients at admission and divided into mild (serum creatinine[SCr] 1.5 to $2.4 \mathrm{mg} / \mathrm{dl}$ ), moderate (SCr 2.5 to 3.9 $\mathrm{mg} / \mathrm{dl}$ ) and severe (SCr $\geq 4 \mathrm{mg} / \mathrm{dl}$ ) renal dysfunction ${ }^{2}$. Study patients were divided into two groups on the basis of serum creatinine. Patients having SCr $<1.5 \mathrm{mg} / \mathrm{dl}$ were group-I and $\mathrm{SCr} \geq 1.5$ were group-II.

ECG analysis: Terminal portion of the QRS complex in two or more consecutive leads were analysed by 3 experienced physicians and in case of uncertain ECG classification, two other physicians were consulted. The investigators analyzing ECGs were blinded to clinical data of the patients. Anterior localization and number of leads with ST segment elevation were analyzed. The patients were classified into two ECG pattern groups on the basis of presence or absence of terminal QRS distortion.

Without distortion: Those with tall symmetric $\mathrm{T}$ waves and ST elevation in two or more adjacent leads without major changes in the configuration of the terminal portion of the QRS complex (Fig-I and Fig-2).

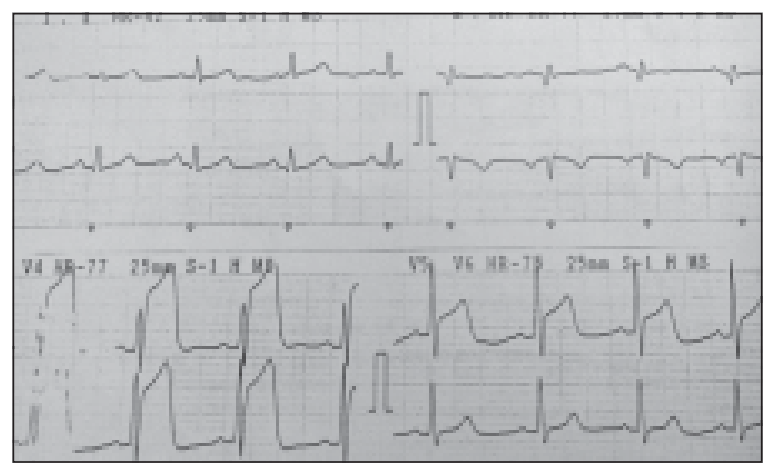

Fig.-1: Mr. X, 50 years admitted in BSMMU in CCU, bed3 on 22.03.2015 with the complaints of severe chest pain and ECG at admission showing acute STEMI anterior with serum creatinine $1.1 \mathrm{mg} / \mathrm{dl}$. There is presence of $S$ wave in leads V3, V4 and V5 in Leads with Rs configuration, without distortion of the QRS.

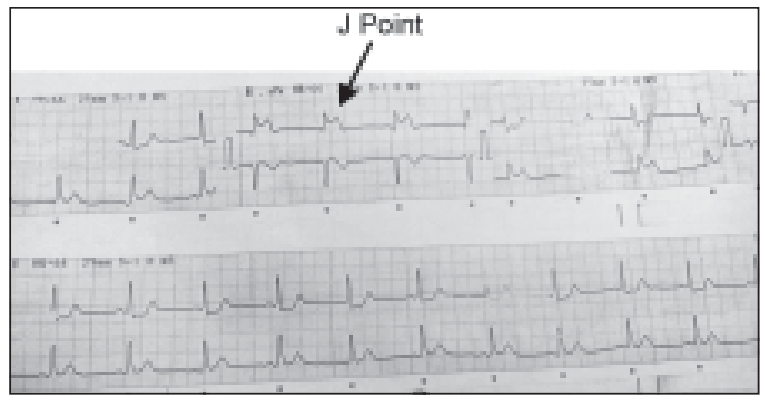

Fig.-2: Mr. X, 77 years admitted in BSMMU in CCU, Bed 4 on 28.02.2015 with the complaints of severe chest pain for 1 hour and ECG at admission showing acute STEMI inferior with serum creatinin $0.9 \mathrm{mg} / \mathrm{dl}$, J point emergence below $50 \%$ of the $R$ wave amplitude, without distortion of the QRS.

With distortion: Those with tall symmetric $\mathrm{T}$ waves and ST elevation and distortion of the terminal portion of the QRS complex in two or more adjacent leads. These groups were further divided into pattern $\mathrm{A}$ and pattern $\mathrm{B}$.

Pattern A: The height of the $\mathrm{R}$ wave and $\mathrm{J}$ point were measured. Emergence of the J point at or above the lower half of the $\mathrm{R}$ wave ( $\geq 50 \%$ of the $\mathrm{R}$ wave amplitude as measured from isoelectric line) in leads with qR configuration (Fig-3).

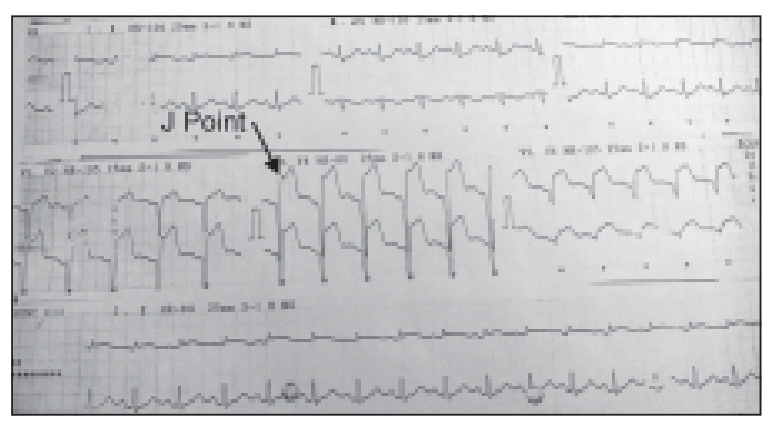

Fig.-3: $M r . X$, 45 years admitted in BSMMU in CCU -2 on 20.02.2015 with the complaints of severe chest pain for 10 hour and ECG at admission showing acute STEMI extensive anterior with serum creatinine $4.6 \mathrm{mg} / \mathrm{dl}$. J point emergence more than $50 \%$ of the $R$ wave amplitude in leads V1-V6, 1 and aVL in Leads with qR configuration, pattern $A$.

Pattern B: Absence of $\mathrm{S}$ waves in leads with Rs configuration (leads without Q waves). (Fig-4).

Outcomes: The analysis of the inhospital clinical course including the occurrence of death and heart failure. Heart failure was assessed by Killip class classification. 


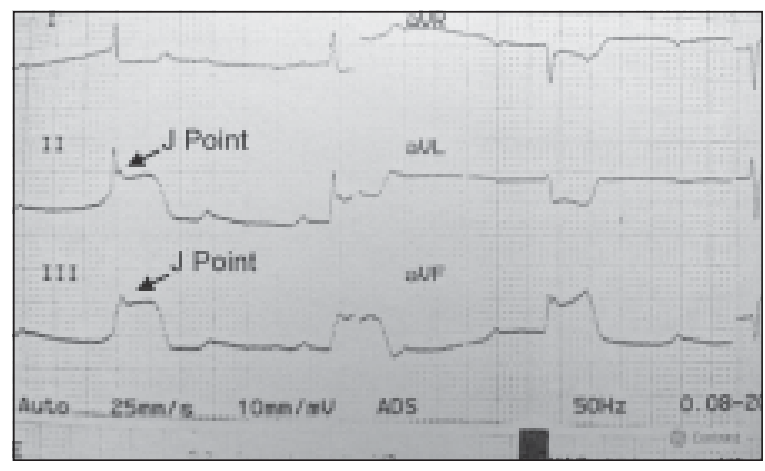

Fig.-4: Mr. X, 55 years admitted in BSMMU in CCU -2 on 22.01.2015 with the complaints of severe chest pain for 3 hours and ECG at admission showing acute STEMI inferior and complete heart block serum creatinine 2mg/ dl. Absence of $S$ wave in leads II, III and aVF in Leads with Rs configuration, pattern $B$.

Statistical analysis: Data was analysed by using statistical package for social sciences (SPSS) version 20. Qualitative data expressed as percentage and difference between two groups were analysed by Chi-square test. Quantitative data expressed as mean \pm SD and difference between two groups were analysed by unpaired two tailed t test. Multiple logistic regression analysis were done to exclude confounding variables for adverse events. Odds ratio was analysed to assess the risk of imposed QRS distortion for adverse cardiac events. p value $<0.05$ was considered for statistically significant.

\section{Results:}

A total number of 60 patients were included in the analysis, 44 STEMI without CKD and 16 STEMI with CKD. There were 30(50\%) patients with QRS distortion. The distribution of all patients are presented in figure 5 . The mean age was $53.57 \pm 10.91$ and $61.50 \pm 9.93$ in group 1 and group II respectively. Patients of group II were significantly older age $(p=0.014)^{2,6}$. The comparison of clinical and ECG characteristics between CKD and without CKD patients are shown in table1. There were no statistically significant difference in risk factors, door to needle time and anterior location of MI in between two groups. Patients with STEMI and CKD had significantly higher killip class at admission $\mathrm{p}=0.002$ and $\mathrm{QRS}$ distortion on admission ECG ( $\mathrm{p}=0.008)$.

The inhospital outcome was significantly worse in CKD groups (Table 2). There were 7 deaths, 2 in without CKD and 5 in CKD groups $(\mathrm{p}=0.004)$. The cause of death was left ventricular failure (2), cardiogenic shock (2), and arrhythmias (3). Out of 60 patients heart failure was 16 and significantly higher in STEMI with CKD group $(\mathrm{p}=0.001)$ and uneventful recovery was significantly higher in without CKD groups $(\mathrm{p}=,<0.001)$. Multiple logistic regression analysis showed that independent predictors of QRS distortion were Killip class ( $\geq$ II) and CKD (serum creatinine $\geq 1.5 \mathrm{mg} / \mathrm{dl}$ ) (Table 3).

Table-I

Clinical and electrocardiographic data according to s.creatinine level $(n=60)$

\begin{tabular}{lccc}
\hline Characteristics & $\begin{array}{c}\text { Group-I } \\
\left(\begin{array}{c}\text { S.creatininen } \\
<1.5 \mathrm{mg} / \mathrm{dl}) \\
(\mathrm{n}=44)\end{array}\right.\end{array}$ & $\begin{array}{c}\text { Group-II } \\
\text { (S.creatininen } \\
\text { e”1.5mg/dl) } \\
(\mathrm{n}=16)\end{array}$ & P value \\
\hline Mean age (years) & $\begin{array}{c}53.57 \pm 10.91 \\
39(88.6 \%)\end{array}$ & $61.50 \pm 9.93$ & $0.014^{*}$ \\
Sex- Male (\%) & $25(56.8 \%)$ & $16(100.0 \%)$ & 0.159 \\
Diabetes mellitus & $24(54.5 \%)$ & $9(56.3 \%)$ & 0.969 \\
Hypertension & $22(50.0 \%)$ & $8(50.0 \%)$ & 0.755 \\
Smoking & $4.02 \pm 3.04$ & $11(68.8 \%)$ & 0.197 \\
Mean time to thrombolysis (hrs) & $7(15.90 \%)$ & $5.03 \pm 2.81$ & 0.252 \\
Killip class (e"II) & $24(54.5 \%)$ & $9(56.25 \%)$ & $0.002^{*}$ \\
Location of AMI (Anterior) & $21(47.7 \%)$ & $9(43.8 \%)$ & 0.459 \\
No of leads with ST segment elevation (e” 5) & $17(43.2 \%)$ & $13(66.25 \%)$ & 0.559 \\
QRS distortion & & & $0.008^{*}$ \\
\hline
\end{tabular}


Table-II

Inhospital outcome according to S.creatinine level $(n=60)$

\begin{tabular}{lccc}
\hline Outcome & $\begin{array}{c}\text { Group-I } \\
\left(\begin{array}{c}\text { S.creatininen } \\
<1.5 \mathrm{mg} / \mathrm{dl}) \\
(\mathrm{n}=44)\end{array}\right.\end{array}$ & $\begin{array}{c}\text { Group-II } \\
(\text { S.creatininen } \\
\geq 1.5 \mathrm{mg} / \mathrm{dl}) \\
(\mathrm{n}=16)\end{array}$ & P value \\
\hline Death & $2(4.5 \%)$ & $5(31 \%)$ & $0.004^{*}$ \\
Heart failure & $7(16 \%)$ & $9(56 \%)$ & $0.001^{*}$ \\
Uneventful recovery & $35(80 \%)$ & $2(12.5 \%)$ & $<0.001^{*}$ \\
\hline
\end{tabular}

Table-III

Predictors of QRS distortion

\begin{tabular}{lccc}
\hline Independent predictors on multivariate analysis & OR & $95 \%$ CI & P value \\
\hline Killip class $\geq$ II & 3.578 & $1.085-11.795$ & 0.036 \\
$\mathrm{CKD} \geq 1.5$ & 5.702 & $1.420-22.889$ & 0.014 \\
\hline
\end{tabular}

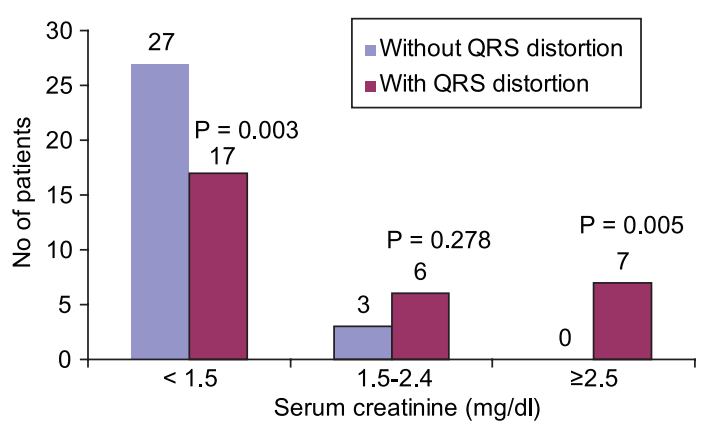

Fig.-5: Patients distribution according to the presence of QRS distortion and s.creatinine level categories as normal ( $<1.5 \mathrm{mg} / \mathrm{dl})$, mild $(1.5-2.4 \mathrm{mg} / \mathrm{dl})$ and moderate to severe $(\geq 2.5 \mathrm{mg} / \mathrm{dl})$ renal impairment.

\section{Discussion:}

Acute coronary syndrome and chronic kidney diseases are highly prevalent worldwide and associated with worse outcomes. Outcome after MI depends on infarct size which influenced by residual blood flow to the infracted area either by antegrade flow or by collateral circulation ${ }^{7}$. An ECG, a source of decisive data that may obtain within 10 minutes after arrival of patients with a history of chest discomfort consistent with acute coronary syndrome ${ }^{8}$. The role of ECG in diagnosis and prognostication of acute myocardial infarction is well established. The morphology of QRS on admission ECG in patients with STEMI suggest the grade of ischemia, absence of distorted QRS indicate grade 2 ischemia and presence of distortion of QRS indicate grade 3 ischemia that was predictive of more extensive myocardial involvement and greater severity of regional dysfunction ${ }^{9}$. This study tried to analyze the prevalence of distorted QRS on admission ECG in patients with STEMI with CKD and its influence on their prognosis.

The extent of myocardial infarction can also be estimated by Echocardiography, radionuclide ventriculography, myocardial perfusion scintigraphy, and magnetic resonance imaging (MRI) ${ }^{7}$. Positron emission tomography and X-Ray computed tomography (CT) are less common ${ }^{10}$. But the imaging methods such as Echo and radionuclide ventriculography increases delay in starting treatment and can neither measure the severityof ischemia nor differentiate between viable myocardium and already infracted myocardium ${ }^{7}$. Although single photon emission computed tomography (SPECT) with 99 mTc sestamibi can quantify residual flow to infarct area and the size of the area at risk and allow the viable myocytes to be imaged but this methods are also time consuming, expensive, technically demanding and not easily available $e^{7,10}$.

The purkinji system is less sensitive to ischemia than the contracting myocardial cells. Distortion in the terminal portion of the QRS to occur when more severe degree of ischemia that would injure the purkinji system ${ }^{11,12}$. Distortion of the QRS is caused by alteration in the conduction velocity of the activation wave in the purkinji fibers as it travels through the ischemic region. The delayed conduction decreases the degree of cancellation and, by so doing, increase the amplitude of the $\mathrm{R}$ wave and causes loss of the S wave ${ }^{11,12}$. 
All though the management of STEMI with CKD remains controversial, our group had a very similar approach to the management of these patients compared to without CKD, all patients receiving thrombolytic therapy. CKD patients were less likely to receive angiotensin converting enzyme inhibitors or angiotensin receptor blockers at discharge.

Some other study showed there was no difference in the primary management strategy (Medical, Percutaneous coronary intervention, coronary artery bypass grafting) or in the type of stent used in between two groups ${ }^{13}$. CKD patients were older in compared with those without CKD $(\mathrm{p}=0.014)$ that also similar to other study ${ }^{2,6,13}$.

The mean door to needle time did not showed statistically significant difference between two groups. Birnbaum et al. ${ }^{11}$ found time interval to be significant when thrombolysis to be performed e" 2 hrs and was associated with increase inhospital mortality only among patients with QRS distortion and not in patients without QRS distortion, patients who were treated within 2 hrs of onset of symptoms there was no difference in mortality between two groups ${ }^{11}$.

Our patient's Killip class $\geq$ II $15.90 \%$ and 56.25\% respectively in group I and group II. These parameters showed the higher Killip class in group II (p value < 0.002) which was observed by various study ${ }^{6,13}$. Higher the Killip class indicate larger area of myocardial necrosis and higher incidence of heart failure and increase mortality.

Regarding the ECG findings of these patients population only the QRS distortion were significant, location of anterior MI and number of leads with ST elevation in group I and group II did not showed any significant difference. Terminal portion of QRS distortion on admission was a better predictor of final infarct size than number of leads with ST segment elevation ${ }^{7}$. Patients with 8 or 9 of out of 12 leads showing ST segment elevation have three or four times of mortality of those with only 2 or 3 leads demonstrating ST segment elevation ${ }^{14}$. Birnbaum (2001) ${ }^{15}$ stated that the number of leads with ST elevation had only mild correlation with myocardial dysfunction but no correlation with severity of dysfunction. Patients with QRS distortion had smaller proportion of salvaged myocardium event after percutaneous coronary intervention, and more often develop heart failure ${ }^{16}$. Severity of ischemia correlate with the degree of distorted QRS complex ${ }^{16}$.

Previous work suggested that CKD patients have calcium and phosphate abnormalities, sodium and volume overload, endothelial dysfunction associated with uremic condition, LDL oxidation and oxidative stress with monocyte stimulation leading to smooth muscle proliferation, accelerated atherosclerosis, increase thrombin level, coronary calcification, decrease coronary perfusion and diastolic dysfunction ${ }^{2,13,17}$. All these factors are likely to be responsible for more severe ischemia and absence of collateral to the infarcted area in CKD patients. Some authors suggested that absence of collateral to the infracted area could be responsible for sever degree of ischemia and assessed by ECG with the presence of QRS distortion ${ }^{16}$. QRS distortion were more frequent in patients with moderate to severe CKD ( $\mathrm{p}=0.005)$. Increase serum createnine ( $\geq 1.2 \mathrm{mg} / \mathrm{dl}$ for women and $\geq 1.5$ $\mathrm{mg} / \mathrm{dl}$ for men) had a 2.7 fold greater risk of acute MI or death from coronary artery diseases ${ }^{2}$.

The outcome of the study population, death was $4.5 \%$ and 31\% respectively in group I and group II. Heart failure was 16\% without CKD group and 56\% in CKD group. These parameters showed difference were significant between two groups ( $\mathrm{P}$ value $<0.05$ for these parameters) and similar pattern had also been found among many other studies $2,6,13$. Patients with distorted QRS complex had absence of collateral blood flow, larger area of myocardial necrosis and difficult to salvage the jeopardized myocardium even after reperfusion therapy. So this group of patients had more tendency to develop heart failure and death. Previous study showed ${ }^{1}$ CKD patients had poor prognosis even after percutaneous coronary intervention or coronary artery bypass grafting ${ }^{1}$. So there is greater importance of primary prevention and risk factor modification to prevent the progression of CKD and cardiovascular diseases.

Among the patients of CKD with QRS distortion (68.8\%), 5 patients were died, 5 heart failure and rest of the patients had uneventful recovery.

In multiple logistic regression analysis, CKD (serum creatinine $\geq 1.5 \mathrm{mg} / \mathrm{dl}$ ) and Killip class (e”II) were independent predictors of QRS distortion $(\mathrm{OR}=5.702$, $\mathrm{p}=0.014$; OR=3.578, $\mathrm{p}=0.036$; respectively).

The correlation between heart and kidney diseases is known as cardiorenal syndrome (CRS). There are 5 types CRS. CRS type 4 is a situation in which CKD may increase the risk of adverse cardiovascular events ${ }^{2,17}$. In this study, we have showed that serum creatinine and killip class are independent predictors of the appearance of QRS distortion, and that CKD patients with QRS distortion carries the poor prognosis. This ECG findings identifies patients with more severe degree of ischemia and probably 
endothelial dysfunction, accelerated atherosclerosis and poorer collateral development. These factors help to explain the adverse outcome of patients with STEMI with CKD.

\section{Conclusion}

Careful analysis of ECG which is simple, cheap, universally available, bed side investigation may offer important prognostic information in patients with STEMI with CKD. $\mathrm{CKD}$ is an independent predictor of the appearance of QRS distortion on admission ECG in patients with STEMI. With the presence of QRS distortion, the CKD patients can be stratifying promptly and help in identify who had severe ischemia.

\section{Reference:}

1. Coats WC and Dellsperger KC. Advances in percutaneous coronary intervention in patients with chronic kidney diseases. Advances in peritoneal Dialysis 2010;26

2. Rodrigues FB, Bruetto RG, Torres US et al. Effect of Kidney Diseases on Acute Coronary Syndrome. Clin J Am Soc Nephrol 2010;5:1530-36

3. Garcia-Rubira Jc, Perez-Leal I, Garcia-Martinez JT et al. The initial electrocardiogram pattern is a strong predictor of outcome in acute myocardial infarction. Int J Cardiol, 1995; 51:301-05.

4. Garcia-Rubira Jc, Garcia-Borbolla R, Nunez-Gil I et al. Distortion of the terminal portion of the QRS is precdictor of shock after primary percutaneous coronary intervention for acute myocardial infarction. Int J Cardiol, 2008; 130:241-45.

5. Steg PG, James SK, Atar D et al. ESC Guidelines for the management of acute myocardial infarction in patients presenting with ST-segment elevation, 2013.

6. Lawesson SS, Alfredsson J, Szummer K et al. Prevalence and Prognostic impact of Chronic Kidney Diseases in STEMI from a gender perspective: data from the SWEDEHEART register, a large Swedish prospective cohort. BMJ open 2015;5.

7. Mulay DV \& Mukhedkar SM. Prognostic significance of the distortion of terminal portion of QRS complex on admission electrocardiogram in ST segment elevation myocardial infarction. Indian heart journal, 2013; 65: 671-77.
8. Sabatine MS \& Cannon CP. Approach to The Patient with Chest Pain. In: Mann, Dl, Zipes, DP, Libby, P (eds), Bonow, Ro, Braunwald's heart disease, A text book of cardiovascular medicine, 10th edn, Elsevier, Phyladelphia; 2015: 1057-67.

9. Luna AB, Goldwasser D, Fiol M et al. Surface echocardiography. In: Fuster, V, Walsh, R \& Harringlon, RA (eds), Hurst's The Heart, 13 $3^{\text {th }}$ edn, McGraw Hill, New York, 2011; 343.

10. Kim Mc, Kini AS \& Fuster V. Definitions of Acute Coronary Syndromes. In: Fuster, V, Walsh, R \& Harringlon, RA (eds), Hurst's The Heart, $13^{\text {th }}$ edn, McGraw Hill, New York, 2011; 1287-95.

11. Birnbaum Y, Herz I \& Sclarovsky S, Zlotikamien B, Chetrit A, Olmpr L, Barbash Gi. Prognostic significance of the admission electrocardiogram in acute myocardial infarction. J Am Coll Cardiol, 1996; 27(5): 1128-32.

12. Yang HS, Lee CW, Hong MK, Moon DH, Kim YH, Lee SG, Han KH, Kim JJ, Park SW, Park SJ. Terminal QRS complex distortion on the admission electrocardiogram in anterior acute myocardial infarction and association with residual flow and infarct size after primary angioplasty. The Koren Journal of Internal Medicine, 2005; 20: 21-25.

13. Saltzman AJ, Stone GW, Claessel BE et al. Long- Term impact of Chronic Kidney Diseases in Patients with ST-Segment Elevation Myocardial Infarction Treated with Primary Percutaneous Coronary Intervention. JACC 2011;4:9.

14. Scirica BM \& Morrow DA. ST-Elevation Myocardial Infarction: Pathology, Pathophysiology, and Cilinical Features. In: Mann, Dl, Zipes, DP, Libby, P (eds), Bonow, Ro, Braunwald's heart disease, A text book of cardiovascular medicine, $10^{\text {th }}$ edn, Elsevier, Phyladelphia, 2015; 1068-93.

15. Birnbaum Y, Crigerda DA, Wagner GS, Strasberg B, Mager A, Gates K, Granger CB, Ross AM, Barbash GI. Prediction of extent and severity of left ventricular dysfunction in anterior acute myocardial infarction by the admission electrocardiogram. Am Heart J, 2001; 141: 915-24.

16. Garcia-Rubira, JC, Gil, IN, Borbolla, RG, Lennie, V, Manzano, NC, Cobos, MA, Perez de, IL, Ortiz, AF, Macaya, C. Distortion of the QRS in elderly patients with myocardial infarction, Cardiology journal, 2009; 16(5): 1-xxx.

17. Ronco C, Haapio M, House AA, Anavekar N, Bellomo R: Cardiorenal syndrome. J Am Coll Cardiol 2008;52:1527-39. 